\title{
32 UNDERSTANDING THE EXCHANGE INTENTION OF AN INDIVIDUAL BLOGGER
}

\author{
Wee-Kek Tan \\ Department of Information Systems \\ National University of Singapore \\ Singapore \\ Chuan-Hoo Tan \\ Department of Information Systems \\ City University of Hong Kong \\ Hong Kong \\ Hock-Hai Teo \\ Department of Information Systems \\ National University of Singapore \\ Singapore
}

\section{ABSTRACT}

This research explores the issue of how a blogring, a circle/community of blogs with a common theme (Xanga 2008; Chua and Xu 2007), could be utilized to form a loosely distributed exchange of products for monetary and nonmonetary returns. Specifically, we present a research model that identifies factors influencing a blogger's intention to participate in a commercial exchange, a commercial activity involving a blogger and a reader within a blogring.

A blogring is conceptualized as a natural segmentation of user-alike whereby members (i.e., bloggers and readers) converge toward common interests reflected in the blog contents (Kumar et al. 2004; Gumbrecht 2004). The formation of this social network provides bloggers with the social capital to engage in collaboration and cooperation with other members (Putnam 2000; Peece 2002). Economizing on this social capital, bloggers could engage in product, service, and/or money exchanges. We term this process the

Please use the following format when citing this chapter:

Tan, W-K., Tan, C-H., and Teo, H-H., 2008, in IFIP International Federation for Information Processing, Volume 267, Information Technology in the Service Economy: Challenges and Possibilities for the $21^{\text {st }}$ Century, eds. Barrett, M., Davidson, E., Middleton, C., and DeGross, J. (Boston: Springer), pp. 375-378. 


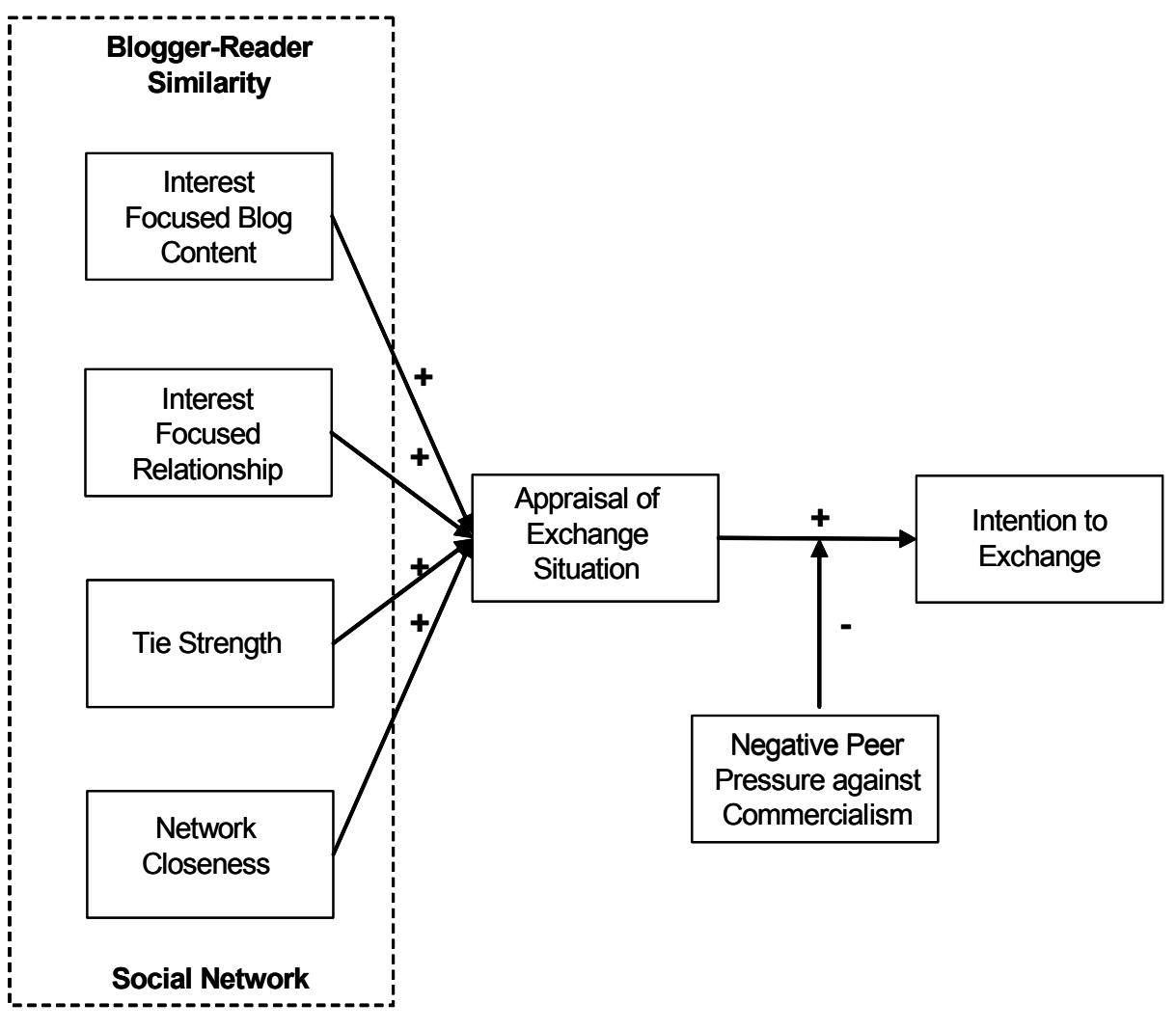

Figure 1. Research Model

economic leverage of personal blog (Balasubramanian and Mahajan 2001). Such an economic leverage includes selling, barter trading, and outright giving away items that can be identified or associated with the shared interests of the blogring. In other words, any exchange between bloggers and readers need not necessarily be for monetary returns but could also involve an exchange of knowledge or expertise in return for approvalrelated utility (Balasubramanian and Mahajan 2001). With this understanding, we next present our research model.

The research model (Figure 1) draws from three streams of literature. First, we reference the similarity attraction theory (Byrne 1971), which posits that people prefer to interact with like-minded others. For instance, salespeople generally prefer to sell to prospects sharing characteristics (e.g., gender and age) with themselves (Dwyer et al. 1998). Hence, we conjecture that bloggers could be more inclined to commercial exchange with readers who have similar interests. We term this blogger-reader similarity. Second, the general premise of the social network dictates that members could place higher priority on relationships and ties with other members within a blogring compared with individuals' personality attributes. Hence, we could posit that the stronger the tie (Frenzen and Davis 1990; Marsden and Campbell 1984) between a buyer and a seller, the 
higher the likelihood for purchase (Frenzen and Davis). Additionally, the closer a reader is to the blogger, the greater the ease of engaging in an exchange due to greater influence exerted by the blogger over the reader (Burkhardt 1994).

Third, building on the decision-making framework proposed by Luce, Bettman, and Payne (2001), we hypothesize that the decision of whether to engage in an exchange depends on the appraisal of the exchange situation, which in turn is influenced by bloggerreader similarity and social network. A positive appraisal should lead to a higher exchange intention from the blogger. However, any negative peer pressure against commercialism exerted by other blogring members could negatively moderate the appraisal (Luce et al. 2001), thus leading to lower exchange intention.

\section{References}

Balasubramanian, S., and Mahajan, V. 2001. "The Economic Leverage of the Virtual Community," International Journal of Electronic Commerce (5:3), Spring, pp. 103-138.

Burkhardt, M. E. 1994. "Social Interaction Effects Following a Technological Change: A Longitudinal Investigation," Academy of Management Journal (37:4), August, pp. 869-898.

Byrne, D. 1971. The Attraction Paradigm, New York: Academic Press.

Chau, M., and Xu, J. 2007. "Mining Communities and Their Relationships in Blogs: A Study of Online Hate Groups," International Journal of Human-Computer Studies (65:1), pp. 57-70.

Dwyer, S., Richard, O., and Shepherd, C. D. 1998. "An Exploratory Study of Gender and Age Matching in the Salesperson-Prospective Customer Dyad: Testing Similarity-Performance Predictions," Journal of Personal Selling \& Sales Management (18:4), Fall, pp. 55-69.

Frenzen, J. K., and Davis, H. L. 1990. "Purchasing Behavior in Embedded Markets," Journal of Consumer Research (17), June, pp. 1-12.

Gumbrecht, M. 2004. "Blogs as 'Protected Space," presentation at the WWW 2004 Workshop on the Weblogging Ecosystem: Aggregation, Analysis and Dynamics, New York May 18.

Kumar, R., Novak, J., Raghavan, P., and Tomkins, A. 2004. "Structure and Evolution of Blogspace," Communications of the ACM (47:12), December, pp. 35-39.

Luce, M. F., Bettman, J. R., and Payne, J. W. Emotional Decisions: Tradeoff Difficulty and Coping in Consumer Choice, Chicago: The University of Chicago Press.

Marsden, P. V., and Campbell, K. E. 1984. "Measuring Tie Strength," Social Forces (63:2), December, pp. 482-501.

Preece, J. 2002. "Supporting Community and Building Social Capital," Communications of the ACM (45:4), April, pp. 37-39.

Putnam, R. D. 2000. Bowling Alone: The Collapse and Revival of American Community, New York: Simon \& Schuster.

Xanga. 2008. "Xanga Help Blogrings FAQ,” (http://www.xanga.com; accessed March 25, 2008).

\section{About the Authors}

Wee-Kek Tan is a graduate student at the National University of Singapore. His research interests include social computing, online decision aid design, and information systems development and education. He has published in conferences, such as ACM SIGMIS CPR. He can be reached by e-mail at tanwk@comp.nus.edu.sg.

Chuan-Hoo Tan is an assistant professor of Information Systems at the City University of Hong Kong. His research interests include agent design, online market institutions, and IT innovation adoption. He has published in reputable journals such as IEEE Transactions of Engineering 
Management and Communications of the ACM, and conferences, such as the International Conference on Information Systems. He can be reached by e-mail at chuantan@cityu.edu.hk.

Hock-Hai Teo is an associate professor of Information Systems at the National University of Singapore. His research interests include IT innovation adoption, assimilation and impacts, information privacy, and electronic market institutions. Dr. Teo has published in many journals including MIS Quarterly, Journal of MIS, and IEEE Transactions on Engineering Management. He can be reached by e-mail at teohh@comp.nus.edu.sg. 